\title{
DAGAARE [a] IS NOT NEUTRAL TO ATR HARMONY
}

\author{
Avery Ozburn *, Samuel Akinbo ${ }^{\dagger}$, Alexander Angsongna ${ }^{*}$, Murray Schellenberg ${ }^{*}$ and Douglas Pulleyblank ${ }^{\#}$ \\ Department of Linguistics, University of British Columbia, Vancouver, British Columbia, Canada
}

\section{Introduction}

Dagaare is a Gur language of the Niger-Congo family, part of a group of languages known as the Mabia languages. It is spoken by about 1.5 million people in northwestern Ghana and some parts of Burkina Faso [1,2].

Dagaare is described as having a nine-vowel inventory, with tongue root contrasts for high and mid vowels, but a single low vowel [a] [1,3]. Dagaare has ATR harmony, in which vowels within a phonological word agree in tongue root features, but the low vowel is described as being neutral to this phenomenon [1].

The present paper describes an acoustic study of $\langle a\rangle$ in Central Dagaare as spoken in Sombo, Nadowli-Kaleo district. Formants of $\langle a\rangle$ were measured in verbal particles surrounded by different combinations of ATR and RTR vowels. Results show that $\langle a\rangle$ is significantly higher and fronted when followed by an ATR vowel compared to when followed by an RTR vowel. This suggests that Dagaare <a> is not in fact neutral to harmony, but instead has two significantly different variants depending on whether it occurs in an ATR or RTR context, as in Figure 1.

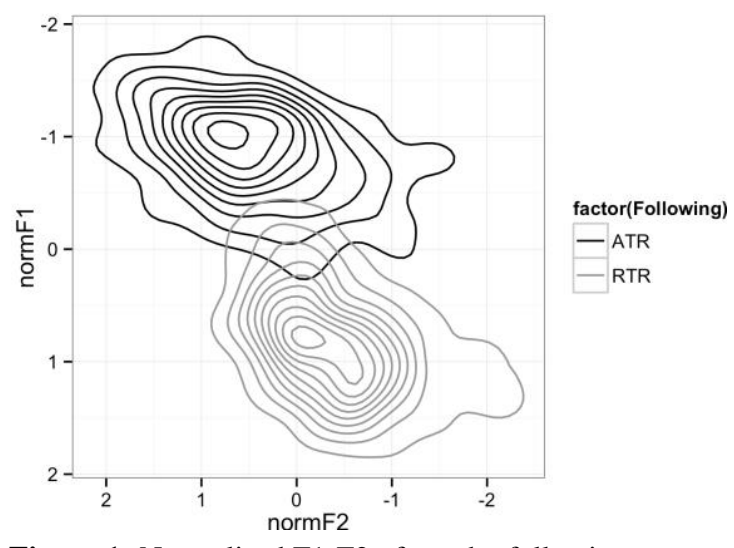

Figure 1: Normalised F1-F2 of $<a>$ by following context

\section{Methods}

Data come from 5 male native speakers of Dagaare (ages 32 to 50). Data were collected in Nadowli-Kaleo district, Ghana. The data were elicited in a soundproofed room with a Shure WH30 headset microphone at a sampling rate of
48kHz: 16Bit.

The stimuli contain the target $\langle a>$ in verbal particles, between different ATR/RTR combinations in carrier phrases. A sample of the stimuli is given in Table 1.

Table 1: Carrier phrases with <a> between ATR/RTR vowels

\begin{tabular}{|c|c|c|c|}
\hline Preceding & Following & Target & Gloss \\
\hline ATR & ATR & Báj[úó] tá [dí] dííbú & $\begin{array}{l}\text { 'Bájúó, don’t } \\
\text { eat food' }\end{array}$ \\
\hline RTR & RTR & Bàj[’̀̀] tá [dí]béyé & $\begin{array}{l}\text { 'Bájọọọ, don't } \\
\text { take beans' }\end{array}$ \\
\hline ATR & RTR & Dàb[ùó] tá [dí] à nén & $\begin{array}{l}\text { 'Dábùó, } \\
\text { don't take } \\
\text { meat' }\end{array}$ \\
\hline RTR & ATR & Bàj[j̀̀] tá [dí] dííbú & $\begin{array}{l}\text { 'Bàjọọọ, don't } \\
\text { eat food' }\end{array}$ \\
\hline
\end{tabular}

\section{Results}

Vowels of interest were segmented manually in Praat [4], and a script was used to extract F1 and F2 values at the 50\% point. Since all particles behaved the same way, we combined them for the purposes of the analysis. The mean F1 and F2 values for each condition are given in Table 2.

Table 2: Average formant values in each condition

\begin{tabular}{|c|c|c|c|}
\hline Preceding context & Following context & F1 (Hz) & F2 (Hz) \\
\hline ATR & ATR & 450.93 & 1567.66 \\
\hline RTR & ATR & 463.84 & 1560.70 \\
\hline ATR & RTR & 591.03 & 1450.36 \\
\hline RTR & RTR & 613.73 & 1424.22 \\
\hline
\end{tabular}

As is evident, F1 values are substantially higher when the following context is ATR than when it is RTR; F2 values in the same context are lower. There is also a slight, but much smaller, difference in F1 and F2 in the same directions based on preceding context.

Formant values were $\mathrm{z}$-score normalized for each participant, in order to increase comparability across different speakers. The boxplot in Figure 2 shows normalized F1 by following context for all speakers and all particles; Figure 3 shows the same for F2. The same clear distinction as in Table 2 holds in these figures.

\footnotetext{
*avery.ozburn@alumni.ubc.ca

$\dagger$ akinbosk@gmail.com

†.ansong@ubc.ca

-mschell@mail.ubc.ca

\# douglas.pulleyblank@ubc.ca
} 


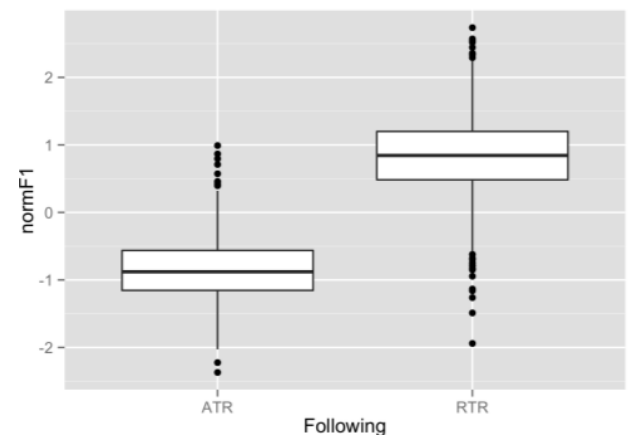

Figure 2: Normalized F1 by following context

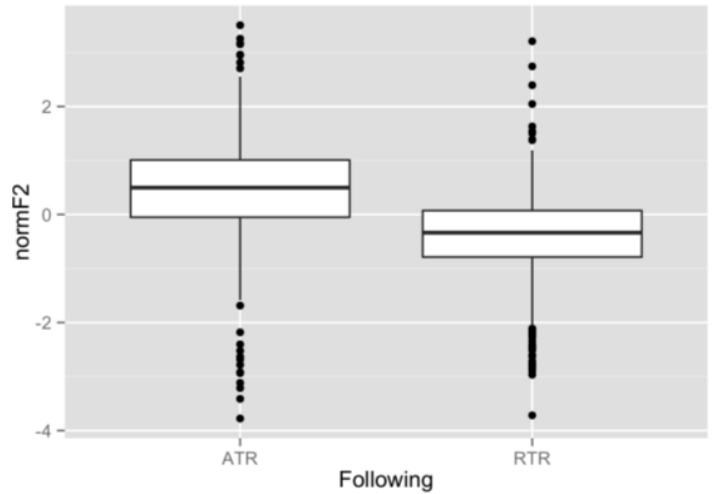

Figure 3: Normalized F2 by following context

We fit linear mixed effects models to determine the significance of these effects. The dependent variables were normalized F1 and F2, and the fixed effects were preceding context, following context, and their interaction. Subject and word were included as random effects, with preceding and following context as random slopes for both. ATR was used as the reference level for both fixed effect factors.

Following context was a significant effect on both normalized F1 and normalized F2 ( $\mathrm{t}=11.060$ and $\mathrm{t}=-6.165$ respectively). The direction of the difference was positive for F1 and negative for F2, indicating that F1 is significantly higher while F2 is significantly lower with following RTR contexts, compared to following ATR contexts. Preceding context was not a significant effect on either of F1 or F2 $(t=1.182, t=-0.310$ respectively), nor was the interaction between preceding and following context $(\mathrm{t}=0.496, \mathrm{t}=-0.738$ respectively). Note that a $t$ value above 2 is the cut-off for significance.

We additionally extracted formant measurements at the $25 \%$ and $75 \%$ points to confirm whether the effect is present through the entire vowel. As seen in Figure 4, there is a substantial difference in F1 value based on following context at all positions. Linear models with the same structure as described for the data from the $50 \%$ point were run for both the $25 \%$ and $75 \%$ point, confirming that the effect of following context on F1 and F2 is significant at all three points.

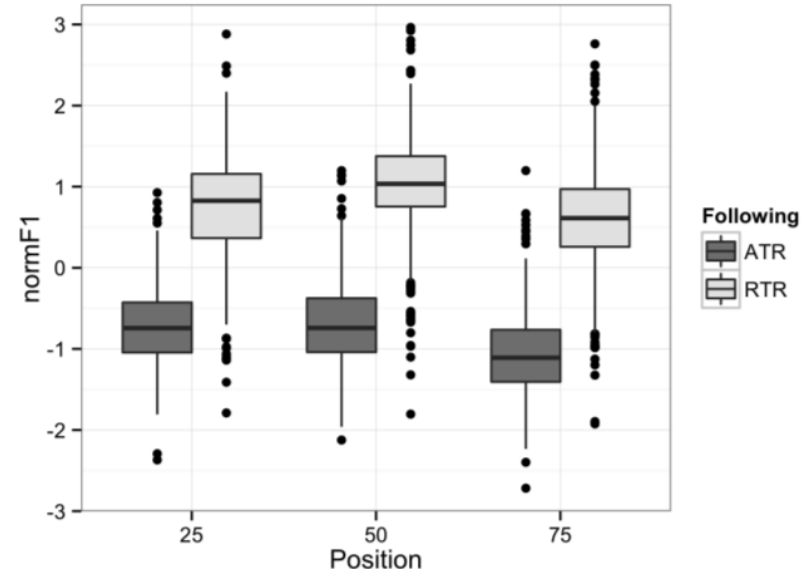

Figure 4: Normalized F1 by position and following context

\section{Discussion and conclusions}

The results show substantial, significant $\mathrm{F} 1$ and F2 differences for $\langle\mathrm{a}\rangle$ in contexts where an ATR vowel follows versus ones with a following RTR vowel, suggesting that $\langle a\rangle$ is raised and fronted in ATR contexts. These differences were present for all speakers and all verbal particles. This suggests that Dagaare $\langle a\rangle$ is not a single vowel that is neutral to harmony. Instead, it is significantly different in RTR versus ATR contexts. Moreover, this difference is maintained throughout the vowel, suggesting that the effect is phonological, rather than phonetic coarticulation.

Overall, this study has shown that Dagaare [a] is not neutral to ATR harmony. Instead, there is a significant difference in $\langle a\rangle$ when it is followed by ATR versus RTR vowels; the former context is raised and fronted compared to the latter. This suggests the possibility that there are two low vowels in Dagaare, [a] in RTR contexts and $[\Lambda]$ in ATR contexts, which should be investigated in more detail in future work.

\section{Acknowledgments}

We would like to acknowledge Angsongna Yendor Roger, Anthony Duusuuri, and members of Kaleonaa family for sharing their language with us. This research is part of the project funded by SSHRC Insight grant (\#435-2016-0369) awarded to Douglas Pulleyblank.

\section{References}

[1] Bodomo, Adams. The Structure of Dagaare. Stanford Monographs in African Languages. Stanford, CA: CSLI, 1997.

[2] Kennedy, Jack. Collected Field Reports on the Phonology of Dagaari. Collected. Collected Language Notes. vol. 6, 1966.

[3]. Kropp Dakubu, Mary Esther. Collected language notes on Dagaare grammar 26. University of Ghana: Institute of African Studies, 2005.

[4]. Boersma, Paul. Praat, a system for doing phonetics by computer. 9/10, s.1. : Glot International, vol. 5, pp. 341-345, 2001. 